Revista Iberoamericana, Vol. LXXI, Núm. 210, Enero-Marzo 2005, 145-164

\title{
ORFANDAD. CONFIGURACIONES DE UNA FIGURA EN LA LITERATURA ESCRITA POR MUJERES EN CENTROAMÉRICA $(1975-2000)^{1}$
}

\author{
POR \\ BARBARA DRÖSCHER \\ Freie Universitat Berlin
}

No deja de ser sorprendente la frecuencia en la literatura latinoamericana de huérfanas, de protagonistas femeninos cuyos rasgos y posición los determina la pérdida temprana de los padres. Se trata de huérfanas. Ya sea que hayan crecido en casa de los abuelos o de otros parientes, con padres adoptivos o con un padre, los textos atribuyen a estas mujeres ciertos rasgos exclusivos. La pérdida temprana de la protección de los padres, particularmente de la madre, les otorga un sello de personajes especiales, sobre todo en el contexto cultural en el que se inscriben: sociedades selladas en el catolicismo, en las que "la familia" es vista como la estructura social fundamental. ${ }^{2}$ Sociedades en las que, por ejemplo, fórmulas como "no tienes madre” son un insulto. Más precisamente, al tratarse de personajes femeninos, el estatus especial de la orfandad conlleva a una situación ambivalente. Con la orfandad se asocian tanto soledad, desamparo y peligro o propensión a la enfermedad como también cierta excentricidad, independencia y extravagancia. La interrupción de la relación padres-hija/ madre-hija que marca la figura, puede leerse como una metáfora de la ruptura de la continuidad en el proceso de reproducción de las relaciones sociales y abre así un espacio para nuevas proyecciones y para la negociación discursiva de las posiciones en las relaciones entre los sexos y de la imagen de la mujer en la literatura latinoamericana.

También en la literatura escrita por mujeres en América Central en el último cuarto del siglo xx, nos topamos frecuentemente con la figura de la huérfana. En la mayoría de las novelas en que una mujer aparece como personaje principal, la protagonista ha quedado huérfana en su primera infancia o siendo niña. Esto es válido, por ejemplo, para Olga, en la novela de Carmen Naranjo titulada Sobrepunto [concluida en 1976 y publicada en 1986] y para Mariana, en la novela de Gloria Guardia El último juego [1976]. Lo mismo puede decirse de las hermanas Leticia y Paula en Siete relatos sobre el amor y la guerra [1986],

\footnotetext{
${ }^{1}$ Agradezco a la traductora Jimena A. Prieto su ayuda para la versión de este texto al castellano. ${ }^{2}$ Aun cuando las estructuras familiares en América Latina muestran fuertes diferencias según el contexto social y/o étnico e, históricamente vistas, se encuentran en un proceso de constante transformación, la imagen cristiana de la familia (en la que la madre, el padre y el hijo constituyen el núcleo familiar) representa aún la norma discursiva. Esto sigue siendo aplicable hoy en día a Centroamérica, aún cuando el análisis social muestra que actualmente "hablar en Centroamérica de 'la familia' es un mito vacío de sentido” (Fauné 39).
} 
de Rosario Aguilar; de Sofía, en Sofía de los presagios [1990] y de Melisandra en Waslala [1996], de Gioconda Belli. Finalmente, vale también para la figura femenina de Esmeralda, en Libertad en Llamas [1999], de Gloria Guardia. ${ }^{3}$ Estas novelas: Sobrepunto de la escritora costaricense Carmen Naranjo, El último juego y Libertad en Llamas de la escritora panameña Gloria Guardia, y las novelas de las escritoras nicaragüenses Siete relatos sobre el amor y la guerra, de Rosario Aguilar, y Sofía de los presagios y Waslala, de Gioconda Belli, forman el corpus de este artículo que pretende representar un aspecto de las reconfiguraciones de la imagen de la mujer en la literatura latinoamericana contribuidas por escritoras centroamericanas.

La orfandad como tropo literario no es algo nuevo. Ya en las foundational fictions de América Latina, la orfandad de las heroínas - de Amalia, María o Doña Bárbaraconstituye una condición esencial para la narración. Las deficiencias en materia de vínculos familiares integrativos o la libertad respecto a ellos es el elemento que hace posible en principio la constelación dramática y determina a la vez el papel que la respectiva figura femenina representa dentro de la construcción discursiva de la nación. Todo hace pensar que en el siglo xx serían sobre todo las escritoras quienes recurren en determinadas épocas a la orfandad como elemento para la construcción de sus figuras femeninas, marcando así un quiebre en la reproducción de las construcciones tradicionales de género y, sobre todo, valorando posiciones feministas en el contexto de la transformación social. Francine Masiello ha mostrado cómo autoras de la Vanguardia latinoamericana se apropiaron de la figura de la huérfana, ${ }^{4}$ para escapar, mediante el rompimiento simbólico de la genealogía, de la construcción de la familia estructurada patriarcalmente, y de su lógica. ${ }^{5}$ La orfandad se convierte en "la única posibilidad de salida para la mujer en la sociedad” (Masiello 811 y s). En comparación con otras constelaciones literarias de la relación madre-hija, ${ }^{6}$ la radical y abrupta separación de la madre, contenida por definición

\footnotetext{
${ }^{3}$ También en dos novelas históricas sobre la Conquista y los tiempos de la Colonia, encontramos a las huérfanas como personajes claves, aun cuando no sean protagonistas como ocurre con Doña Leonor en La niña blanca y los pájaros sin pies [1992], de Rosario Aguilar, y con Catarina, en Asalto al paraíso [1992], de Tatjana Lobo. El análisis de la función de la huérfana en la discusión sobre el mestizaje como metáfora en la construcción de identidad latinoamericana en estas novelas desborda los límites de este artículo.

4 "Predominan en estos libros huérfanas, personajes solitarios y jóvenes adolescentes que se ven obligadas a abandonar su casa y a cambiar de vivienda” (Masiello 810).

5 "En primer lugar, la novela de vanguardia inicia un cuestionamiento de la genealogía como índice de la identidad personal; con ello se repudia la figura paternal como eje de los procesos de significación social. En segundo lugar, con el desafío de los orígenes familiares, también surgen nuevos nexos entre los personajes; mediante este proceso se destacan las relaciones laterales -las amistades entre mujeres u otros sustitutos de la familia- que superan las jerarquías verticales dominadas por el pater familias. El proceso da por resultado una necesaria reestructuración del yo de la protagonista y una nueva conciencia de su cuerpo, junto a su novedosa relación con objetos del entorno inmediato. Finalmente, esta exploración llega, en su máxima realización, a un desafío del logos masculino, destinado a liberar los procesos de significación de su contexto común” (Masiello 808).

${ }^{6}$ Como se puede ver por ejemplo comparando tres novelas de autoras mexicanas: Balún-Canán [1957], de Rosario Castellanos; La "Flor de Liz" [1988], de Elena Poniatowska, y Mejor desaparece [1987], de Carmen Boullosa (Dröscher 1999).
} 
en la orfandad, parece ser un tropo de gran utilidad, cuando se trata de elaborar literariamente, como en tiempos de la Vanguardia, procesos dinámicos de transformación social y las correspondientes modificaciones en la construcción de género.

Tanto en María [1867], Amalia [1855], Doña Bárbara [1929] y en las novelas de las escritoras de la Vanguardia, así como en las novelas centroamericanas del último cuarto del siglo xx que forman el corpus de mi estudio, la orfandad proporciona la precondición necesaria para que la protagonista llegue a configurar un papel extraordinario en la narración, frente a lo que es la determinación de la mujer dentro del discurso contemporáneo dominante. Sin embargo, mientras que en las foundational fictions este papel tenía su función en la construcción discursiva de la imagined community, en América Central en el último cuarto del siglo xx, la figura de la huérfana marca más bien los límites de los proyectos políticos puestos bajo los estandartes de la liberación nacional. De esta manera las novelas contribuyen a la deconstrucción de ciertos mitos nacionales y del mito de "la familia".?

Al parecer, la orfandad no es sólo una condición para que estas figuras femeninas tengan una posición exclusiva en la estructura social representada, sino que fundamenta una "anomalía” en las relaciones sexuales entre los géneros, cuando se comparan esas protagonistas con la imagen de la mujer en sociedades dominadas por el catolicismo. Una acentuada sensualidad y, en casi todos los casos, un deseo erótico femenino propio -ya sea éste realizable o no- las determina y las aleja definitivamente de la imagen tradicional de la virgen inocente, la madre casta o la esposa asexuada. Masiello afirma que "las protagonistas de Bombal, Lange y de la Parra eluden el compromiso erótico para proteger su libertad” (814), es decir para escapar a la reducción al estatus de objeto en el discurso del otro, sea del marido, del hijo o del padre. La libertad que conquistan de esta forma les permite, según Masiello, dejarse definir en su identidad no a través de la herencia y la reproducción, sino a partir de su propio cuerpo. En esta forma la negación de la relación erótica representa para las escritoras de Vanguardia un instrumento para afirmar el libre poder de disponibilidad sobre el propio cuerpo. Todo lo contrario sucede en las novelas centroamericanas: el derecho a la disposición sobre el propio cuerpo no se realiza a través de la continencia sexual, sino más bien en la articulación de un fuerte y propio deseo sexual por parte de las protagonistas. La orfandad simboliza en América Central no sólo la resistencia contra el poder paterno dentro de estructuras familiares patriarcales, sino que en primer plano aparece la ausencia de la madre como aquel elemento que señala el rompimiento con el papel tradicional de la mujer. Puede decirse que estas protagonistas comparten como rasgo definitorio no dejarse clasificar dentro de los esquemas tradicionalmente prescritos para las mujeres cuando no son madres ni vírgenes: ser puta. Como hace decir Carmen Naranjo en su novela Sobrepunto a la protagonista Olga: "Se vive libremente y las mujeres han dejado de temer al sexo y se acuestan con quien les da

\footnotetext{
${ }^{7}$ Se puede ver una semejanza aquí con las autoras de la vanguardia, como lo nota Masiello: "Como hemos indicado, la narrativa del mundonovismo recopila este proyecto, correlacionando familia y Estado, y la autoridad del individuo y la historia nacional. Las novelas que comentamos hoy [de Teresa de la Parra, Norah Lange yo María Luisa Bombal] desafían este proceso, explotando las contradicciones involucradas en la unidad mujer-familia-Estado” (Masiello 813).
} 
la gana” (41). Es justamente la orfandad la que les da la pauta de la libertad respecto a esa forma “moderna” de autodeterminación sexual. Sin embargo, tienen que pagar por ello el alto precio de la exclusividad y de cierta extraterritorialidad respecto a una sociedad que se rige por normas tradicionales. De todas maneras, la posición social y los recursos materiales juegan un papel determinante. A diferencia de las protagonistas de las autoras de la Vanguardia, ${ }^{8}$ en estas novelas centroamericanas escritas por mujeres las protagonistas no están arruinadas económicamente como consecuencia de su estado de orfandad. Más bien, la orfandad les permite gozar, ${ }^{9}$ como en Amalia, de una independencia material fuera de lo común.

En las primeras novelas en las que aparece el personaje de la huérfana, escritas en los años setenta en América Central, el deseo sexual se constituye como una dimensión irrealizable. La búsqueda de una relación satisfactoria con hombres se produce en vano y las historias terminan por lo general con la muerte de la protagonista. A mediados de los años ochenta aparece una constelación nueva. Las novelas de las autoras centroamericanas narran entonces historias de una sexualidad femenina vivida en forma plena. Simultánamente, el deseo y con él la necesidad de autodeterminación, articulada a través del mismo deseo, se han expandido hacia una nueva dimensión: trasciende claramente el campo de la intimidad para dirigirse hacia la participación activa en procesos sociales.

Hay que señalar, sin embargo, que en la figura de la huérfana y la determinación de su deseo, no se trata de elaborar literariamente experiencias biográficas por parte de las autoras, ${ }^{10}$ sino de analizar la forma como se representan la posición de las mujeres, situando a las huérfanas en el contexto de los conflictos sociales que están representados en sus novelas. Lo que cuenta, por consiguiente, en los textos de estas autoras centroamericanas producidos en el último cuarto del siglo xx, es su alto grado interdiscursivo y la claridad y concesión de las referencias a conflictos políticos reales y a relaciones sociales precisas. En América Central han tenido lugar cambios sociales y culturales notables, a partir de los proyectos de reforma política de los años cuarenta en Guatemala y Costa Rica y el impulso a la modernización económica adelantada en los años cincuenta. Estos cambios encontraron también expresión, sobre todo a partir de los años sesenta, en las modificaciones en la posición de la mujer, y se vincularon a la lucha discursiva en la que se decidía el qué es ser mujer y cómo se es mujer. Mientras que la orfandad en general en este contexto determinado por fuertes cambios sociales parece ser una figura particularmente adecuada para tratar el cambio de la posición de las mujeres, las diversas reconfiguraciones en la representación del personaje de la huérfana remiten a la dinámica de los cambios sociales y culturales. Las soluciones a los varios tipos de problemas, elaborados con la metáfora de la orfandad, corresponden al desarrollo de los discursos de

\footnotetext{
8 “todas las mujeres son desheredadas de sus propiedades”(Masiello 811).

${ }^{9}$ Con excepción de las hermanas en Siete relatos sobre el amor y la guerra.

${ }^{10}$ En las entrevistas que llevé a cabo, las autoras señalaron que ellas mismas crecieron en ambientes de familias tradicionales y casi todas mantuvieron buenas relaciones con sus madres. Tampoco se vieron a sí mismas reducidas al campo de la intimidad. Carmen Naranjo, por ejemplo, fue una de las primeras mujeres que ocuparon altas posiciones públicas como jefa del Seguro Social, ministro y embajadora.
} 
autocomprensión por parte de las mujeres y al surgimiento de un nuevo movimiento de mujeres en la región.

En las novelas El último juego de Gloria Guardia y Sobrepunto de Carmen Naranjo, se narran las historias trágicas de mujeres de clase alta, ${ }^{11}$ que han crecido sin padres pero con independencia económica. Su deseo erótico, en conjunción con su resistencia a someterse al rol tradicional de la mujer, desemboca en la muerte. Llama la atención que en estas novelas centroamericanas de los años setenta, el narrador es un personaje masculino. En ambas, la historia personal de este personaje está ligada al acontecer político, con lo que se logra enlazar alegóricamente la historia de las huérfanas a la historia de la nación. A través de la perspectiva de la simpatía de este personaje hacia las protagonistas, se va entretejiendo el acontecer que desemboca en la muerte de éstas. No obstante, la estructura fragmentaria moderna ${ }^{12}$ de la narración permite una toma de distancia con respecto a las formas falocéntricas de narrar, haciendo un uso subversivo de la intertextualidad en el sentido de Julia Kristeva.

En la novela Sobrepunto de Carmen Naranjo, a partir de recuerdos impregnados de amor, un amigo ("Yo") cuenta la historia de Olga, una mujer desgarrada entre los esquemas tradicionales de comportamiento y sus necesidades de libertad (sexual), que a través de una persecución vana y autodestructiva termina por perderse a sí misma. Mediante extractos de un diario y fragmentos evocados del pasado, Carmen Naranjo hace que el narrador dibuje de manera puntillista, "punto por punto", ${ }^{13}$ la historia de Olga hasta su suicidio, intercalada con su propia historia, que es a la vez su historia de amistad y amor hacia Olga, tan bien insatisfecha como inquebrantable. De sus recuerdos surgen conversaciones y encuentros, pero también breves episodios. A través de la evocación narrativa del "Yo", una mirada de amor impregnada de ironía cariñosa y un deseo más insinuado que dicho, el lector obtiene una imagen atrayente de Olga: una mujer con sed de libertad y de amor; con un carácter cariñoso y espontáneo; abierta y fascinante pero también caprichosa, egocéntrica y mimada. La relación que el narrador establece con Olga es de comprensión paternal y, a la vez, está marcada por la imposibilidad de sustraerse a su atractivo.

La historia trágica de Olga comienza con una experiencia traumática: a muy temprana edad fue brutalmente separada de la madre por los abuelos y adoptada finalmente por ellos. Olga crece sin recibir afecto de parte de ellos, en un mundo que se revela como superficial, tanto en lo emocional como en lo espiritual. Desde niña se encuentra rodeada de una

\footnotetext{
${ }^{11}$ Todavía en el año 1986, Carmen Naranjo explica la elección del medio social haciendo referencia a la libertad específica de las mujeres de las altas capas sociales, cuya visión está impregnada por una mentalidad pequeño-burguesa: "Es de la clase alta, porque esa clase te permite un montón de cosas que no te permite la clase pobre, para tratar problemas de la mujer en una sociedad como la actual” (Carmen Naranjo, en: Pincón Garfield 227).

${ }^{12}$ Amelia Mondragón (1993) presenta las dos novelas como contribuciones esenciales al surgimiento de la novela moderna en América Central.

13 "En Sobrepunto interviene mucho el dibujo, la novela está elaborada con la técnica del puntillismo usando las palabras como si fueran puntos. Por eso se llama así. "Sobrepunto" es una palabra que no figura en el diccionario, pero significa punto sobre punto”, Carmen Naranjo, en "Entrevista con Luz I. Martínez” (Martínez 335).
} 
riqueza ostentosa a la que, no obstante, nunca se siente vinculada. A pesar del estatus de clase alta de los abuelos, Olga va a ser estigmatizada a causa de su madre, una prostituta alcohólica, hundida en la miseria y excluida de la alta sociedad. También el hecho de haber pasado su infancia en el extranjero convierte a Olga en una extraña en su medio social. A partir de los fragmentos del narrador, puede reconstruirse el desarrollo de la vida de Olga, desde que era una joven mimada hasta su condición de esposa frustrada que ni ahora ni antes acepta las normas de la sociedad, al mismo tiempo que se entrega a una incansable lucha por el afecto y el reconocimiento. Olga se opone obstinadamente a las rígidas normas de la sociedad que la rodea. Es expulsada de la escuela de monjas, no sólo porque entra en conflicto con las reglas de castidad, sino también porque choca contra las normas sociales de su clase cuando besa a un joven jardinero. Con una sed insaciable de amor, sólo con dificultades consigue pretendientes en la clase alta. Perfectamente maquillada, los provoca, los saca de su reserva. Olga anda en busca de vivencias sexuales y de pasión. Espera alcanzar con ellas encuentros de gran intensidad e, incluso, un anclaje en la vida; y aunque no le importa nada el mandamiento de la castidad, oscila constantemente entre transgredir y observar las convenciones.

Olga se une con otros jóvenes en una actitud de apoyo a las acciones armadas de un grupo insurgente, poco antes del establecimiento de la democracia en Costa Rica en 1948. Sin embargo, este compromiso político termina por convertirse en un juego inacabado. La incansable búsqueda de ser percibida y amada, la ata tan intensamente como los privilegios materiales a las prescripciones de su clase. La participación en la vida social de la clase alta hace necesario el disfraz, la puesta en escena. Sin embargo, estas poses le resultan a la larga insostenibles. Una vez que su matrimonio fracasa y los hijos le son arrebatados, se acelera el círculo vicioso de deseo, enamoramiento, decepciones y desesperación. A pesar de su independencia económica, no encuentra un lugar en el tejido social de su clase. Las relaciones familiares no le ofrecen estabilidad ni ayuda. En la búsqueda de la madre, retrocede desconcertada ante la posibilidad del encuentro real. Olga comparte el juicio de su medio social sobre la madre, y experimenta la fuerza de su deseo sexual como su "herencia” fatal. Cada nuevo intento de encontrar la felicidad fracasa, lo que la arrastra una y otra vez a una búsqueda obsesiva. Los intentos de suicidio se convierten en un constante grito de auxilio. Olga se refugia en las drogas, para sentirse por lo menos en la embriaguez. Finalmente, este círculo vicioso termina con su muerte.

La historia de Olga refleja una constelación social en la que no hay lugar para mujeres dominadas por un fuerte deseo propio; éstas son cuerpos extraños en la "buena” sociedad, y están, por esta razón, condenadas a desaparecer. Por otra parte, la estructura fragmentada de la narración abre desde una perspectiva amigable con la protagonista, un espacio para que los recuerdos evocados puedan interpretarse como denuncia social y crítica de las normas tradicionales. El "Yo" al que Carmen Naranjo otorga esta percepción no es una mujer sino un personaje masculino relativamente ajeno a la imagen tradicional del macho en América Central; un hombre sensible, que sufre por la situación social del país y por haber fracasado respecto a las expectativas de Olga. A través de su compromiso personal con el desarrollo político de Costa Rica, la historia de Olga se vincula al fracaso de los proyectos de reforma del país, vinculados a la Revolución de 1948. A causa de este vínculo, esta novela puede leerse en forma alegórica, en el sentido de Doris Sommer (42) 
El empleo de una posición narrativa masculina que reflexiona sobre la situación política, remite, por una parte, a la carencia de una voz femenina que tenga la autoridad necesaria para narrar los acontecimientos; por otra parte, al hecho de que la limitación al hogar, como lugar prescrito para la mujer, no es una posibilidad viable para Carmen Naranjo. Mientras que la protagonista fracasa trágicamente en la realización de un deseo vital femenino, la autora toma posición en el discurso del deseo y, a la vez, en el campo político-social. La narración articula duelo, desesperación y, al final, indignación ante el destino de Olga, la huérfana. En la medida en que Carmen Naranjo relaciona el fracaso del deseo de Olga al fracaso del proyecto de reforma social, la crítica a las limitaciones de autodeterminación sexual se torna en una crítica de las relaciones sociales y políticas. La autora reclama con ello no sólo el derecho al propio cuerpo, sino también una posición crítica en el proceso político y social de América Central.

\section{El ÚLTiMO JUEGO}

También en la novela de Gloria Guardia titulada El último juego, de 1977, la historia de Mariana, una huérfana, se vincula alegóricamente a la historia del país, en este caso Panamá. Tanto en la relación amorosa entre Garrido, el protagonista masculino, y Mariana, así como en el conflicto del Canal de Panamá, la novela trata la cuestión de la soberanía. La acción dramática encuentra su momento clave en el asalto a la casa de Garrido, quien representa la posición panameña dentro de las negociaciones con los Estados Unidos para rescindir el tratado del canal. Garrido y sus huéspedes, entre quienes se encuentra Mariana, son tomados como rehenes por un comando del movimiento de independencia de Panamá. La acción guerrillera persigue como meta la liberación de presos políticos y poner de manifiesto las exigencias de independencia nacional. La experiencia traumática de una violación de la esfera privada por la acción guerrillera evoca, si bien bajo signos contrarios, la violación de la soberanía a través de la presencia de tropas americanas en el canal de Panamá (Rodríguez 22). Mariana muere por un disparo accidental durante la ocupación de la casa por el comando de la guerrilla. La agudización del conflicto en torno del canal por la toma que realiza el comando guerrillero, es un recurso literario de Guardia. Mientras que la novela se mantiene fiel a los hechos históricos en lo que atañe a la reconstrucción de la historia del canal, la ocupación de la casa nunca tuvo lugar en la historia real de Panamá. Esta acción-tal como lo hará pocos años más tarde Gioconda Belli en La mujer habitada- está inspirada en el asalto a la residencia de José María (Chema) Castillo, en Managua, en 1974. Sin embargo, a diferencia de la heroína de Gioconda Belli, la pareja protagonista en la novela de Gloria Guardia no se decide a apoyar a la guerrilla ni tampoco está situada por el relato en el centro de la acción. Garrido y Mariana son rehenes durante la ocupación, y representan a la clase alta panameña, una clase que, en el contexto del conflicto del canal, oscila entre apoyar al régimen militar y realizar su proyecto de modernización dependiente de los Estados Unidos, sin ser capaz de desarrollar un proyecto propio.

La imagen de Mariana, al igual que la de Olga en Sobrepunto, va a ser trazada retrospectivamente a través de la visión masculina del protagonista. El monólogo interior 
de Garrido, impregnado de melancolía (Rodríguez 24), se sitúa un día después de la ocupación de la casa y de la muerte de Mariana. Este hecho trágico constituye el punto de partida de la narración, en la que serán evocadas escenas de la historia de amor entre ellos, junto a fragmentos relativos a la historia política y de la familia. Mariana aparece desde la perspectiva del narrador como una mujer moderna de clase alta, un espíritu independiente con grandes pretensiones intelectuales, madura, con claridad y seguridad en sí misma, y como una alternativa particularmente atractiva frente a la imagen de la esposa tradicional, representada por Queta. Mariana vive sola, es libre e independiente y, a diferencia de Olga en Sobrepunto, se afirma a sí misma como mujer autónoma en la high society de Panamá. No obstante, resulta ser también un ejemplar exótico y, hasta cierto punto, ajeno a la sociedad. A pesar de no ser costumbre en su posición social, Mariana trabaja en la administración, aunque el empleo le aburre. A diferencia de la superficial Queta, que imita con pésimo gusto the way of life norteamericano, Mariana es retratada como una mujer soberana. Al haber estado en un colegio en los Estados Unidos y hablar inglés tan fluidamente como el español, se siente en casa en diferentes culturas. La forma segura con la que Mariana vive en plenitud su sexualidad, la hace tanto más atractiva a los ojos de Garrido. A él le fascinan su libertad sexual y su extraordinaria capacidad de gozo. Su franqueza y su capacidad de hablar abiertamente así como su actitud crítica e irónica lo impresionan. ${ }^{14}$ El carácter y la presencia fuera de lo común de Mariana, sobre todo en contraste con Queta, tiene su fundamento en una biografía de huérfana. Sus padres murieron en un accidente, pasó su niñez y juventud sin padres, creció entre lujo y soledad bajo la férula de dos tías mayores, una vida que define como un infierno. Todo ello la dota ya desde su juventud, ante los ojos de Garrido, de una extravagancia y un exotismo propios. Su biografía como huérfana la convierte a la vez en objeto de atracción y hace de ella una extraña en su medio social. Siendo una mujer sumamente deseada, al mostrar en la relación con un hombre sorprendente fuerza y seguridad, esta huérfana toma como mujer una posición de sujeto en el imaginario de Garrido, un hombre panameño moderno. Sin embargo, Garrido no se encuentra en situación de alcanzar para sí mismo una posición clara y determinada. Por esa razón, Mariana permanece inalcanzable para él. Ella rechaza su propuesta de matrimonio, ya que él no está a la altura de sus exigencias para lograr una relación pareja en términos de igualdad de derechos. Al final de la historia, Garrido regresa a los brazos de su esposa Queta.

Mariana, de piel oscura y cabellos negros, de caderas amplias y ojos oscuros, resalta sobre todo en comparación a Queta, delicada, pelirroja y de ojos claros. La figura de la huérfana, una panameña de color, fuerte y deseable, aparece no sólo como alternativa en las relaciones entre los géneros, sino que también simboliza un Panamá de color, en

14 "Y es que tú has sido, desde que te recuerdo, tan natural, quiero decir, tan franca que a veces hasta rayabas en lo abrupta, Mariana, ... que aún ahora me pones en guardia ante mí mismo, ante mis dudas, ante esta serie de fórmulas y dogmas, que me poseen y que tontamente quieren determinar, incluso, el modo mismo como debiste exteriorizar tus sentimientos ...un desamparo que llamaba a amarte y abrazarte, a poseerte para irme contagiando poco a poco de tu risa clara, de tu mirada abierta, de tu modo directo de enfocar las cosas, de tu curiosidad vital, de tu entrega lenta, de tu ironía misma” (Guardia 153). 
materias étnicas. Su soberanía contrasta con el oportunismo que caracteriza el entorno social en el que se mueven ella y Garrido. Es Mariana quien, durante la toma, hará por lo menos el intento de entrar en contacto con los guerrilleros.

Gloria Guardia maneja la narración de forma que Garrido dirige su monólogo interno a la Mariana ausente. De esta forma, la percepción de Garrido sobre Mariana queda comprobada por la función de Mariana como interlocutora abierta, ya que tiene la capacidad de participar en un discurso complejo, tanto político como personal. Sin embargo, la exigencia de Mariana de ser tomada en cuenta como persona y no sólo como mujer, puede realizarse sólo tras su muerte. En el contexto de confrontación y lucha en cuestiones de independencia nacional, no parece haber una base consolidada o segura sobre la que se pueda mantener su posición. Mariana debe morir para que la narración pueda desplegarse.

Al igual que Carmen Naranjo, Gloria Guardia dispone sólo de una voz masculina para narrar el destino de su huérfana. De manera todavía más fuerte que la autora costarricense, la escritora panameña subraya la diferencia entre autora y narrador. En determinados momentos toma la perspectiva de un narrador heterodiegético, diferenciándose así de la voz de Garrido, y sirviéndose de este punto de vista somete a observación y critica la figura del narrador mismo y con ello su discurso sobre género. La crítica al oportunismo implicado en la posición oscilante de Garrido, respecto a las negociaciones del canal, se une a la crítica de una situación en la que la posición de una mujer segura y autónoma no puede imponerse y está condenada a desaparecer.

La extravagancia de ambas huérfanas-protagonistas, la concentración de su papel en el esquema de acción de las novelas en su actitud como mujeres deseables y como amantes, nos deja ver que se trata de figuras inscritas en un discurso con el que las escritoras reflexionan sobre el alcance de la modernización en lo que toca a los papeles de género. Funcionan como metáforas para señalar un rompimiento con el modelo tradicional del género femenino, y como figuras en las que aparece trazada una nueva subjetividad femenina emergente a través del deseo sexual. La muerte inevitable de ambas huérfanas simboliza los límites con que se topa este cambio radical, y muestra a la vez lo precaria que era, todavía en los años setenta, una posición autónoma femenina. Sin embargo, en la medida en que Carmen Naranjo y Gloria Guardia presentaron esta situación y vincularon el fracaso de la autodeterminación femenina en sus sociedades con el fracaso de los proyectos nacionales, fueron mucho más allá de dar la palabra al mero deseo erótico de sus protagonistas. El que hayan tenido que servirse de voces masculinas subraya el hecho de que en los años setenta todavía las dos autoras se encontraban aisladas; su posición feminista era insólita. De hecho, en ese tiempo no se había desarrollado el nuevo movimiento de mujeres y no se había abierto el espacio requerido para discutir sobre intereses específicos así como concepciones propias de identidad.

\section{LOS AÑOS OCHENTA}

Veremos ahora la situación en los ochenta. En la novela episódica de Rosario Aguilar Siete relatos sobre el amor y la guerra, publicada en 1986, un narrador no personal cuenta historias de mujeres enfocadas desde las perspectivas narrativas de cada una de ellas. El 
campo de acción de estas protagonistas ya no se limita a un espacio íntimo o privado; al contrario de las protagonistas de las autoras de la Vanguardia ${ }^{15}$ y también de las figuras de Olga y Mariana, el trabajo y la política forman parte importante de su mundo. Todas tienen que actuar dentro de un espacio social sumamente conflictivo. Las hermanas Leticia y Paula son dos de estas siete mujeres nicaragüenses en la época de la insurrección y después del derrocamiento de Somoza, cuyo destino se narra. La revolución ha transformado las condiciones tradicionales de la vida de las mujeres y ha expandido a tal grado los límites de la acción y el deseo, que la libertad de las protagonistas está determinada por los rasgos existenciales propios de las situaciones individuales que viven cada una de las siete mujeres de la novela.

Rosario Aguilar se sirve de una posición narrativa heterodiegética, que en virtud de la técnica del discurso indirecto libre se desplaza para adoptar el punto de vista de cada una de las figuras. De allí que la voz narrativa sea también un acompañante comprensivo que sigue a los personajes femeninos y asume sus pensamientos. El carácter fragmentario de la narración refuerza el acento que recae sobre la perspectiva subjetiva, evitando la actitud totalizante de un narrador omnisciente. Los hilos del destino de las protagonistas, ligeramente entretejidos, se rompen en algún momento sin haber desembocado en un final claro y preciso. De allí que no se asista como lector a una solución armónica de los conflictos.

Con Leticia y Paula encontramos dos figuras de la huérfana enmarcadas en otro medio social. La una es maestra y la otra secretaria, y pertenecen a la clase media baja. Después de la temprana muerte de la madre, viven solas, apoyándose mutuamente. La revolución sandinista ha proporcionado nuevas condiciones para la búsqueda de felicidad y realización personal. Leticia, la mayor de las hermanas, se ha ido a la costa caribeña dentro de la campaña de alfabetización. Allí se enamora de su guía miskito Cristy. La narración de su vida comienza cuando, casi a punto de dar a luz, presa de miedo y agotada por la tensión, espera a Cristy en el umbral de su solitaria choza de la Laguna. Leticia se siente sobrepasada por las duras exigencias de la vida en la selva y amenazada de muerte. Cristy regresa, pero está herido gravemente y no puede darle la seguridad que ella necesita. El sueño de Leticia de vivir en la selva caribeña no parece realizable. Tiene que dar a luz sin ayuda, lo que vive como una pesadilla. La experiencia de desamparo ante los peligros de muerte en una naturaleza extraña y en medio de una cultura que le es ajena, son factores que acaban por desatar en ella una crisis que hace tan intensa su nostalgia por un medio ambiente civilizado, que la mueve a partir. Para Leticia, las diferencias culturales entre su medio natal y el adoptado le resultan un abismo infranqueable. El recuerdo de la felicidad de su primera época en la Laguna como un sitio paradisíaco, acentúa el dolor y la desesperación sobre la decisión que tiene que tomar. Cristy insiste en quedarse con el hijo. Leticia está dispuesta a dejar al hijo bajo la custodia del padre y a abandonarlos a ambos para poder realizar su propia vida. De esta manera, Leticia encarna a una mujer que tiene que escapar del rol "natural” de ser madre, para salvar, ya no su vida, sino su propia existencia.

\footnotetext{
${ }^{15}$ Subraya Masiello: “en las novelas de Teresa de la Parra, Norah Lange o María Luisa Bombal las mujeres quedan fuera del mundo de trabajo" (812).
} 
La historia de Paula nos recuerda el melodrama clásico. Es la hermana menor y como ex-guerrillera es ascendida a "mano derecha” de un funcionario en el Ministerio del interior. Paula rechaza los intentos de seducción de los compañeros sandinistas, ya que encuentra sus ofertas amorosas poco sólidas. El sueño de tener una boda con vestido blanco y una familia feliz no cabe en su vida cotidiana de militante sandinista, lo que la hace entrar en conflicto con sus convicciones políticas. Paula se deja embaucar por un joven casado de clase alta. Su porte distinguido y los regalos con que la colma la impresionan y hacen que su autoestima mejore. Embarcada en esa relación amorosa, termina embarazada. Finalmente, acaba como madre soltera, con una hija enferma que sólo puede ser tratada en el extranjero. Después de que los Estados Unidos le niega la visa, obtiene finalmente la ayuda de su jefe y su hija puede ser operada en Cuba. Paula regresa avergonzada al amparo partriarcal del movimiento sandinista. De esta manera es acogida no por la familia, sino por una nueva red social. Su sueño de bienestar y felicidad familiar se quiebra. No parece existir otra alternativa de realización personal en esa realidad vivida como degradada.

La orfandad resulta aquí menos significativa como impulso para el desarrollo de las dos mujeres que en las novelas arriba mencionadas. Sin embargo, tanto en Leticia como en Paula el estatus de orfandad constituye un factor importante en el marco de la dinámica desatada por la revolución sandinista. Paula siente que a causa de una orfandad temprana y al haber estado en la clandestinidad, ha sido despojada de su juventud. Por lo mismo, parece especialmente predispuesta a la ilusión de un amor ingenuo. "Era como si al quedarse huérfana e integrarse a la clandestinidad, hubiese envejecido por dentro para siempre ... hasta que apareció Eddy” (Aguilar 1986: 48). Para Leticia, a través de la orfandad se acentúa un sentimiento de desorientación en un medio ambiente desconocido: "la orfandad que a veces emanaba desde adentro y que al mismo tiempo podía convertirse en un ser infantil, primitivo, ignorante y libre cuando no enfrentaba problemas que siempre podría resolver” (70). La experiencia de la distancia cultural, vinculada con su decisión de abrirse a una vida y a sentimientos autodeterminados, rebasa las capacidades de Leticia. Paula, por su parte, se mantiene cautiva dentro de los ideales tradicionales de la felicidad. Pero la protección que podría ofrecer una familia pequeño-burguesa en las condiciones de los procesos de transformación que vive la región, resulta una quimera. Sin embargo, la revolución sandinista, en el momento que fija la narración, crea una red social que por lo menos asegura la supervivencia. Casi como ninguna otra novela sobre destinos de mujeres, Siete relatos representa el cambio decisivo de la situación de la mayoría de las mujeres en Centroamérica. A finales de los años ochenta, un tercio de las mujeres de la región son cabeza de la familia. La fragmentación de la sociedad trae consigo la acelerada disolución de las estructuras familiares tradicionales en la región, acarreando a la vez la deconstrucción del mito de "la familia". La difusión del modelo de la familia nuclear constituye una tendencia creciente dentro de las formas de vida modernizadas de la clase alta y media, pero al mismo tiempo los movimientos migratorios y los problemas sociales entre otros factores la deconstruyen y la reemplazan por la formaciones de otros marcos de relación (Faune, 42s).

Existe, sin embargo, un segundo nivel semántico en la figura de las hermanas huérfanas. La orfandad hace posible también una libertad de movimiento en los marcos 
de la solidaridad fraterna. La pérdida de la madre significa para Leticia asumir la responsabilidad de Paula, la hermana menor, al mismo tiempo que la posibilidad de disponer de su vida bajo las condiciones de la realidad social existente con plena libertad.

Pero no sólo la dinámica social y cultural de los procesos de transformación de América Central, sino también el surgimiento de un nuevo movimiento de mujeres representan, en los años ochenta, un cambio fundamental del contexto social en el que se produce la escritura de estas autoras. Este proceso abrió un nuevo espacio discursivo, en que las mujeres pueden comprenderse a si mismas en tanto que mujeres. También tuvo parte en ello la literatura escrita por mujeres, en particular por aquellas que conquistaron el mercado con el rubro de "literatura de mujeres". Este es el contexto en el que asciende a primer plano un aspecto del personaje de la huérfana, que ya representaba un papel significativo en Sobrepunto, la novela de Carmen Naranjo. El estatus de carecer de madre o de padres no es causado en los ochenta por la temprana muerte de los padres, sino por separaciones trágicas, o bien por el abandono. La huérfana se convierte en personaje de un drama en el que el debate sobre la desaparición de la madre se torna en el tema principal de la obra.

Lo mismo puede decirse de Sofía de los presagios, de Gioconda Belli. Mientras en La mujer habitada Belli había reclamado la igualdad de derechos para mujeres de la clase alta en el campo político (Rodríguez, 1994), y la forma interdiscursiva en que le había dado cabida a reivindicaciones fundamentales de las mujeres en esa época -el derecho a una sexualidad femenina, el derecho al aborto y la denuncia del abuso sexual dentro de la familia- había dado a esa novela un grado candente de actualidad (Dröscher 2003), ahora convierte en tema, con la figura de Sofía, la elaboración de la pérdida de la protección materna. La orfandad se convierte en un impulso decisivo en los conflictos por los que Sofía debe pasar en este Bildungsroman. De nuevo el estatus de huérfana representa la precondición necesaria de una posición exclusiva de mujer en el contexto de las relaciones actuales: estigmatizada como apátrida y excéntrica, su desarrollo está determinado por el sentimiento de haber sido abandonada, expresado simbólicamente en un "haberse perdido y haber sido abandonada”, y por una sensación de extrañeza. Por otra parte, esta huérfana posee un anhelo de libertad fuera de lo común y una forma apasionada de deseo. Si se sigue la lógica de la narración, sólo a través de la liberación sexual y de posicionarse socialmente, puede romper el estigma de la orfandad; sólo de esa suerte puede convertir ese estigma en signo de independencia y emancipación personal. Para ello, es necesaria la confrontación con el problema de la pérdida de la madre y el intento de comprender la traición cometida por ella.

A causa de un malentendido trágico, a los siete años Sofía se pierde de sus padres gitanos ambulantes- y es acogida por el terrateniente Don Ramon y la viuda Eulalia, una mujer pobre y de buen corazón. Locos por los encantos de la niña, le dan un nuevo hogar como padres adoptivos. La niña crece bajo la tolerancia y comprensión de los dos viejos, protegida por el bienestar de la hacienda que de adulta heredará. Sin embargo, durante mucho tiempo, se siente extraña en la comunidad campesina; su temperamento libre, sin trabas, es visto muchas veces con desconfianza. Los supersticiosos habitantes del pueblo le adjudican poderes mágicos. Con el apoyo de las fuerzas mágicas de brujas amigas, Sofía lucha por no ser estigmatizada por el pueblo. Por otra parte, logra imponerse como 
empresaria en el sector de la agricultura y se recupera una y otra vez de sus relaciones sexuales fracasadas. La primera de sus pasiones, ajustándose al clisé, la lleva a la sumisión total en los brazos de un hombre que reúne los rasgos típicos del macho latino. El sometimiento a él podrá ser disuelto sólo a través de un acto radical de liberación. Su segunda relación quedará bloqueada por su propia ambivalencia psíquica y la incapacidad de relacionarse realmente con el hombre deseado de manera intersubjetiva. En la tercera, Sofía funcionaliza a un amante casado más moderno y menos machista, procedente de la ciudad, pero al dar a luz, como desea, una hija, cae en una crisis existencial. La relación se invierte, hay una fijación hacía él, pero el amante es incapaz de responder a sus emociones ambivalentes. A diferencia de estas relaciones sexuales fracasadas, tiene con un chamán la experiencia inicial de una sexualidad satisfecha y plena como mujer. Además, la relación con su primo homosexual -que la aconseja y con quien más tarde comparte trabajo y casa- le ofrece una base solidaria para su desarrollo y apoyo en los momentos de crisis. Sofía de los presagios fue publicada en el año en que los sandinistas fracasaron inesperadamente en las elecciones (1990) y la narración parte del supuesto de que los sandinistas lograrían estabilizar el sistema. Mientras que la base social y material parece estar así asegurada en este tiempo, las “conquistas de la revolución” son puestas en tela de juicio en lo concerniente a las relaciones de género. Se trata de la realización del postulado formal de la igualdad de derechos para hombres y mujeres, no sólo con relación al sector productivo y su derecho de disponibilidad sobre el propio cuerpo, sino también de la transformación de las relaciones de género. Esta transformación debía ofrecer posibilidades de desarrollo más allá de los esquemas tradicionales de acuerdo con los cuales "la feminidad es equiparable a ser pasivo, humilde e histérico" y "la masculinidad es equiparable al machismo, a la racionalidad y al dominio”.

Si bien Sofía puede recurrir a las relaciones modernas de trabajo y de derecho, en la novela parecen ser necesarias otras fuerzas para consolidar su proceso de desarrollo en forma exitosa. La protección y el apoyo de fuerzas esotéricas representan un papel esencial en este proceso. Sofía está acompañada de tres ayudantes, una adivina, una curandera y un chamán, cuya fuerza mágica y poder basado en el conocimiento de las fuerzas naturales, podrá influir decisivamente en las circunstancias. Ellos tienen la capacidad de comprender la situación psíquica y social de Sofía, y de abrirle, a través de rituales mágicos, el camino de retorno a sus raíces. La construcción de las propias raíces a través del llamado a una madre primordial, la “Madre Antigua” (Belli 1990: 280), se convierte en elemento clave. La interrupción sufrida en el momento de la orfandad de una tradición corporal por línea materna y la pérdida de seguridad ligada a este acontecimiento van a ser superadas al movilizar las fuerzas de los marginados socialmente -representados por las mujeres sabias, el brujo y el homosexual- sobre la base de una igualdad de derechos de género en lo sexual y lo material.

Ya que Gioconda Belli concibe la carencia de la madre como un motivo central de inquietud y como fuente de inseguridad e histeria, Sofía puede encontrar -como en un proceso psicoterapéutico- a través de la repetición anamnésica la clave para su propia liberación de la relación neurótica con la madre. El objetivo esencial del discurso de identidad feminista de los años ochenta, la búsqueda de identidad como mujer, aparecen así como viables, a través de la reconstrucción de una genealogía femenina no familiar. No 
obstante, el alcance de este concepto de identidad parece ser limitado, pues aún cuando la orfandad suministra el material psíquico de conflicto requerido para que surja un proceso de encuentro consigo misma, no la priva de sus recursos materiales. A diferencia de las protagonistas de las autoras de la Vanguardia, la orfandad le suministra la posición social necesaria para que su historia sea exitosa. Ileana Rodríguez señala que la posesión de las famosas tres “ces”, cara/cuerpo/capital, representa una condición esencial para que este Bildungsroman llegue a un happy-end (Rodríguez 192).

En comparación con la constelación de géneros representada en Doña Bárbara, ${ }^{16}$ se da en Sofía un cambio fundamental. En la versión de Gallegos de la foundacional fiction, es el hombre civilizado proveniente de la ciudad quien impone el progreso y el orden propio del derecho civil burgués en una tierra salvaje, en oposición a una mujer, representante de un peligroso e incontrolable carácter salvaje. Una vez que Santos Luzardo se casa con la hija de Doña Bárbara, una joven que él había domesticado y que convierte en ama de casa, parece estar afianzada la nación, de modo que sus descendientes podrán ser la población civilizada del futuro (Sommer, 281). Muy distinta es la constelación en la novela de Belli: una mujer señalada como salvaje y peligrosa contribuye al desarrollo de un nuevo orden en la periferia de la revolución, a través de su exigencia de autodeterminación e independencia, y apoyada por la solidaridad de personajes construidos como "el otro". El progreso, ligado metonímicamente con el Bildungsroman de Sofía, se consigue mediante una dinámica combinación de productividad económica, movilización del inconsciente, esoterismo y magia tradicional. Sin embargo, la soberanía alcanzada es, al fin y al cabo, precaria. De acuerdo con la narración de Gioconda Belli, esta soberanía requiere de una relación entre hombres y mujeres basada en la comprensión, para que la reproducción de la figura de la huérfana no sea inevitable. Por lo menos así puede leerse el final de la novela, cuando el trauma de perderse vuelve a hacerse presente, y la hija de Sofía se suelta de la mano de su madre. Sin embargo, hay un final feliz: la hija es traída de regreso por el hombre que Sofía ha aprendido a valorar y desear, hablando con él sólo por teléfono. El Bildungsroman concluye con la reconstrucción de la idea de la familia nuclear basada en la heterosexualidad, si bien los roles de género han sido modificados sobre la base de la comunicación.

\section{WASLALA, O UNA NUEVA RECONFIGURACIÓN DE LA HUERFANA}

Seis años más tarde, en 1996, apareció la novela de Gioconda Belli, titulada Waslala. La transformación de la sociedad centroamericana parecía ser un hecho consumado. Los conceptos de género, posmodernidad, comunitarismo y poscolonialismo desde entonces determinan los debates, y las cuestiones de la globalización han reemplazado los conflictos políticos en torno a la independencia nacional. Sin embargo, de nuevo, en este contexto encontramos una (re)configuración de la huérfana y nos ocupa de nuevo el tema de la búsqueda de la madre.

${ }^{16}$ Ileana Rodríguez trata también la relación interdiscursiva entre Doña Barbara y el libro de Belli (1994: 189). 
En una narración que se sitúa en el avanzado siglo xxi, la protagonista Melisandra se encuentra acompañada por un colorido grupo de personas que quieren descubrir la legendaria Waslala. A Waslala habían partido sus padres cuando ella tenía tres años, dejándola a cargo de los abuelos. El haber sido abandonada sella a la actual joven agricultora, de carácter pragmático y activo, con una profunda nostalgia. Sin embargo, en oposición con Sofía, Melisandra está enraizada en su lugar de origen y en sus tradiciones. No obstante, el lugar que habita tiene cierta fluencia, pues se identifica con el río fronterizo del país tropical Faguas, donde está la hacienda de los abuelos. Faguas es una tierra arruinada por conflictos armados, tráfico de drogas e imposición de poder de los caudillos que buscan su legitimación apelando de nuevo a la independencia nacional. Es un país en el que el fin último es poder sobrevivir en medio del los desechos y en la periferia de la hiper-moderna sociedad industrial. Son, sobre todo, mujeres de Faguas quienes desarrollan estrategias pragmáticas de supervivencia.

Melisandra no sólo está enraizada en la vida de la hacienda, sino también en el mundo espiritual del abuelo José. Heredó su amor por la literatura y ha hecho propios sus recuerdos de la utópica Waslala. ${ }^{17}$ Son recuerdos de un proyecto del pasado, una comunidad libre, sin violencia y en la que reina la igualdad social. A lo largo de la novela van surgiendo diversas estaciones de lo que fue Waslala, en un principio fruto de experimento de los poetas. Se puede ver en la producción de leyendas sobre Waslala la necesidad de la utopía y su función para los habitantes de Faguas como imagen invertida del mundo real, es decir un lugar libre de la violencia brutal del presente y portador de esperanzas. Ningún camino real(ista) lleva a Waslala, un lugar utópico en un tiempo “entre-tiempos”. Sólo a través de la intuición es posible llegar hasta allí.

Llama la atención que la búsqueda de este lugar utópico esté vinculada a la de la madre y, en consecuencia, a finalizar el estado de orfandad. Finalmente, Melisandra llega a Waslala y encuentra ahí a su madre. Su padre ha fallecido. Protegido por la madre, Waslala ha quedado ahora como un pueblo paradisíaco que simboliza un concepto ecológico. Hace tiempo que todos los habitantes de este lugar abandonaron el proyecto, con excepción de la madre de Melisandra. Waslala es desencantada, incluso el reencuentro con la madre tiene muy poco de romántico. El encuentro entre ambas se da en términos de una relación madura. Mientras que el desencanto ejerce sus efectos, comienza a surgir el sueño de darle nueva vida en ese lugar utópico. Pero este final no tiene que ser necesariamente así, pues el tiempo exterior se ha quedado suspendido mientras Melisandra ha retornado de Waslala.

La visión más interesante en Waslala es la transformación del concepto de maternidad. Se trata de figuras maternas que asumen la supervivencia, tanto en la realidad como en la utopía. Sin embargo, en Waslala no se encuentra ninguna madre biológica que tenga un papel tradicional de madre. La maternidad no está ya biológicamente fundamentada, sino que es, más bien, un papel elegido. De acuerdo con ello, la relación entre madre e hija se

\footnotetext{
${ }^{17}$ Belli rinde homenaje en la figura del abuelo y de su amigo al escritor nicaragüense Coronel Urtecho y a l poeta Ernesto Cardenal. El igiendo el nombre del pueblo real de Waslala como su lugar utópico hace también referencia a dos poemas de Cardenal, en los cuales el poeta se refiere a Waslala ("Las campesinas del Cuá” y la Cantiga 18 del Cántico Cósmico "Vuelos de victoria”).
} 
modifica también. Se trata de una "relación intersubjetiva” (Benjamin: 19 ss), cuyo fundamento es el reconocimiento del otro como sujeto $y$, a la vez, es el elemento que compensa la orfandad. La metáfora de la ruptura de la relación madre-hija, en la que se trabaja literariamente la del papel tradicional de la mujer, sirve como pre-historia. Aparecen nuevas figuras maternas que representan una imponente tradición de lucha. Melisandra reconoce en Engracia, la gigantesca heroína de los comunitaristas en la lucha contra los caudillos (que recuerdan nolens volens a los hermanos Ortega), a su madre espiritual. Cuando al final halla a su madre biológica, tiene la sensación de que se encuentran dos mujeres adultas, y de que puede perdonarle su traición, al haberla abandonado. Melisandra se ha emancipado de la relación madre-hija, y el trauma del abandono ha sido superado. En este sentido, Waslala se ha convertido en un lugar alcanzable y habitable.

En Waslala la orfandad como estatus sirve más que de impulso para ponerse en marcha. Lejos está aquí la orfandad de ser el detonador de una vida extravagante, de enorme libertad o de un deseo fuera de lo común; tampoco le asigna a la heroína una posición marginal en el espacio social. Casi todas las figuras en esta novela, con excepción de los anacrónicos caudillos, tienen algo de “cruzadores de fronteras": se mueven entre diversas culturas y posiciones de género; se intercambian los papeles de victimario y víctima. La configuración de los géneros se vuelve permeable. Las relaciones homosexuales son, junto a las heterosexuales, al menos para los personajes del norte, lo más normal. En lugar de haber una diferencia fundamental, se da una pluralidad de diferencias. Esta característica se manifiesta también en la polifonía, en la construcción caleidoscópica de las líneas argumentativas y también en el desplazamiento de la posición de las heroínas. En el juego posmoderno con los géneros de las novelas de aventuras, de ciencia ficción, de viajes y de la novela de amor, ya no se trata de producir una voz femenina frente a un discurso totalizante que es expresión del dominio masculino. La tragedia de la orfandad pertenece a la prehistoria.

También en la novela de Gloria Guardia, Libertad en llamas, la narrativa está determinada por la polifonía, la parodia y el transvestismo de los géneros novelescos. A modo de metaficción historiográfica, esta novela transcurre en los años 1928 y 1929 en Nicaragua, la época en que Sandino conduce un movimiento de guerrilla contra los invasores norteamericanos y sus aliados nicaragüenses. La aparición de Esmeralda como protagonista en este conflicto, una intelectual emancipada y mujer segura de sí misma, contribuye a la deconstrucción del mito de Sandino, aún cuando la novela en su conjunto está a favor de la liberación nacional. Apoyada por el poder de los discursos culturales feministas de los años noventa, Gloria Guardia lleva a cabo un experimento: al poner una mujer en el centro de la acción política, logra una estructura históricamente improbable en una novela que, por lo demás, se orienta por los resultados de la historiografía moderna, sobre todo respecto al tema histórico de Sandino. Esmeralda insiste en participar en el conflicto político y se hace cargo de una función que exige gran responsabilidad: ser agente de publicidad, es decir, traductora, mediadora y espía de Sandino. Paralela a una historia de amor en la que aparecen todos los clichés de las películas de aventuras -con delincuentes nobles y sus valientes amantes como protagonistas- se desarrolla dentro de la acción de la novela esa trama política. En la intelectual Esmeralda se muestra otra 
variante de la huérfana que pierde a la madre dentro de la novela posmoderna. Esmeralda es una mujer joven, emancipada y conciente de sí, que-según nos enteramos por el relato de la historia anterior que se cuenta retrospectivamente- perdió a la madre a los trece años. La madre era una mujer abierta y accesible, descendiente de una familia nicaragüense de alcurnia. La huérfana es educada en Madrid por su padre español. En esta ciudad crece y estudia filosofía con Ortega y Gasset. Es precisamente la temprana muerte de la madre lo que parece explicar los rasgos característicos de su personalidad, que la predisponen para tener un papel protagonista en esta novela histórica. Pero no es tanto la muerte de la madre, sino la educación que recibe de parte del padre, y la participación en un proceso masculino de socialización, lo que está así en primer plano. La pérdida de la madre es relevante cuando se trata de cosas de amores. La carencia de un ideal de identidad femenina parece ser el origen de un aspecto de inestabilidad e indefensión. Pero la pérdida de la madre aparece también en el momento en que -con la conciencia de la diferencia en una relación bipolar entre los géneros ${ }^{18} \mathrm{y}$ a través de la estrecha relación con el padre y la introducción en el mundo masculino ${ }^{19}$-surge una base sobre la que se afianza la emancipación. La orientación de acuerdo con el padre y la posibilidad de un mayor espacio libre para experiencias sexuales e intelectuales en la juventud de Esmeralda, crean la posibilidad de rebasar los roles dominantes adscritos a las mujeres en esta época y le abren la posibilidad de participar activamente en la vida política.

Gloria Guardia coloca a su protagonista entre Sandino y su aliado, el intelectual hondureño y modernista tardío Froylán Turcios. En su función de traductora, mediando entre Sandino y la opinión publica internacional, Esmeralda se mueve en un espacio cultural de frontera; se encuentra en una situación de in-between, y acaba por quedar finalmente entre los frentes. En la medida en que desarrolla una posición propia, resultan visibles las diferencias políticas entre ella y Sandino, y se hace sospechosa de traición. Al final, busca la confrontación personal con Sandino, y declara por concluido su apoyo, para regresar a Europa.

La historia política de Esmeralda va a ser complementada con la narración de sus vínculos con el segundo personaje central de la novela, el envejecido artista y dandy Frutos. Esmeralda participa en su proyecto, la creación de una estatua como alegoría del deseo de libertad del pueblo nicaragüense, para lo que utiliza a Clara, una joven que bajo

\footnotetext{
18 “allá en Madrid, en la soledad de mi cuarto, súbitamente realicé que, tras la muerte de mamá, estaba frente a mi condición de mujer [...], orfandad que me negaba el diálogo con un ser similar a mí, a mis sueños, a mis delirios y, sobre todo, a mis dudas inmensas. Y fue entonces (ahora lo sé), cuando fui descubriendo, no sólo la belleza y originalidad de mi cuerpo, sino también cuando fui haciendo conciencia de que mis sensaciones y percepciones, poco o nada tenían que ver con el cuerpo y el modo de ser de ese varón adulto que era mi padre” (Guardia 1999: 223).

19 "Y es que hay qué ver, lo mío (mi lucha por afirmarme libremente a través de actos) ha sido algo que se inició a mis trece años cuando, tras la muerte de mamá, quedé a merced de la férrea voluntad y altiva personalidad de papá. Comprendí el reto que significaba plantearme ante él y medirme antes su verbo afilado. Vislumbré, entonces, la necesidad de saber expresarme con precisión como mujer porque la palabra me revelaba y me confirmaba mi poder frente a él; y porque ésta, lúcidamente escogida, era la fuerza que me permitiría superar todo complejo de inferioridad que su presencia lograba inspirarme” (Guardia 1999: 230).
} 
las condiciones de poder imperantes acaba por morir trágicamente en "las llamas de libertad”. Para una posición mediadora no hay un espacio estable en esta novela. El romance entre la mujer de clase alta, emancipada y formada en Europa, y el revolucionario nicaragüense, fracasa a causa del carácter jerárquico de la guerrilla de Sandino. La posición mediadora en la que Esmeralda busca imponerse, se muestra finalmente, en vistas de la configuración política dada -en particular, del poder imperialista norteamericanocomo impotente e insostenible (Dröscher 2002).

Mientras en la novela la tradición de la lucha de liberación nacional en Nicaragua se somete a una revisión relativamente escéptica, Gloria Guardia reconstruye en la voz de su protagonista Esmeralda una posición feminista que, a primera vista, resulta menos crítica. Sin embargo, la imagen de una mujer fuerte y emancipada que presenta el narrador omnisciente en el primer capítulo, es relativizada más tarde a través de la propia voz de Esmeralda en su diario con dudas sobre sí misma y de una exagerada y excesiva forma de autoasegurar su estatus de mujer emancipada. Esmeralda define su posición de mujer cultivada, marcando una diferencia respecto al "mundo machista" de los hombres: "Y es que, mientras hombres como él [Sandino] y Moncada buscan dominar, someter, conquistar y, tal vez, subyugar, algunas mujeres intentamos descifrar, interpretar, extractar y resumir el porqué de nuestra presencia en la sociedad y en la tierra... Cada experiencia la observamos, no como parte de una historia, ni tampoco como un acontecimiento de la narración lineal que para el hombre es la vida, sino por lo que ésta nos toca, nos hiere, nos marca y nos transforma desde un primer momento la psíquis; esa alma que nos define y diferencia de los demás seres humanos" (Guardia 1999: 222). La conciencia femenina del cuerpo que con la pérdida de la madre se hace presente constituye en este discurso la base de un modo de ver el mundo diferente al de los hombres. En este aspecto las ideas que Gloria Guardia le adjudica a su figura Esmeralda en los años veinte, son similares a la construcción de identidad a través de la experiencia del cuerpo, tal y como Masiello la reconstruye en su lectura de las novelas de vanguardia de mujeres autoras. Esmeralda no sufre tanto por ser huérfana, sino que más bien, como en las autoras feministas, articula la orfandad y abre así el discurso sobre la identidad femenina. Su posición tiene mucho más en común con la actitud de las autoras de la Vanguardia que con los personajes trazados por ellas. Por otra parte, las reflexiones en torno a la construcción social de los géneros remiten a los textos de Simone de Beauvoir. La posición de Esmeralda en el campo intelectual y político corresponde más a la tradición del primer movimiento de emancipación femenina, con su exigencia de participar en el mundo dominado por los hombres, que a la tendencia fuerte del feminismo de los años ochenta, que bajo la influencia de teorías feministas francesas insistió en conceptos esenciales de género.

En relación con Clara, se hacen perceptibles los límites del discurso emancipatorio de Esmeralda, de manera que su posición feminista resulta contextualizada. El contacto con Clara lleva a Esmeralda a la impaciencia y la frustración: Clara sólo puede ir paso a paso, actuando de acuerdo con lo que experimenta como sus propios intereses: "Estoy segura de que la pobre comprendió poco o no entendió nada, quizá, de lo que traté de explicarle” (230). Sin embargo, cuando Clara toma su primera decisión propia y convierte la estatua de la libertad en su propio proyecto, bajo las condiciones imperantes todo termina trágicamente con la muerte. Con su heroína Esmeralda, Gloria Guardia ha inscrito 
el discurso feminista centroamericano dentro de una tradición situada fuera del mundo periférico, y remite con ello al conflicto de las metas respecto al concepto de libertad dentro del movimiento feminista que, vigente desde los años ochenta, nutre entre tanto la discusión entre diversas fracciones en América Latina.

Tanto en la última novela de Gioconda Belli como en la ficción histórica de Gloria Guardia, puede notarse un desplazamiento de la figura de la huérfana, respecto tanto de sus enfoques en los años setenta como en los ochenta. En los años setenta, con la orfandad se mostró un rompimiento y se representó una situación precaria. En los ochenta, la orfandad funcionó como impulso para la búsqueda de soluciones al problema de las genealogías y como punto de partida para la construcción de nuevas posiciones de las mujeres en la sociedad. Al llegar los años noventa, lo mismo en Wasala que en Libertad en llamas, la crisis vinculada a la orfandad pertenece a la prehistoria; sabemos que esta crisis ha sido ya superada hace tiempo, y que una posición autónoma por parte de las mujeres es algo no solamente posible sino evidente. El juego anacrónico con la historia y con el tiempo en la novela posmoderna permite que mujeres emancipadas y posiciones femeninas fuertes resulten personajes consistentes. Los conflictos más interesantes en estas novelas dependen de nuevas constelaciones, en donde lo que está en juego son posiciones entre los frentes tradicionales. El desplazamiento corresponde también a la transición de la diferencia a las diferencias, a la vez que nos recuerda que la precondición histórica para la percepción de las diferencias fue articular y marcar la diferencia.

BiBLIOGRAFÍA

Aguilar, Rosario. Siete relatos sobre el amor y la guerra. San José: EDUCA, 1986. La niña blanca y los pájaros sin pies. Managua: Nueva Nicaragua, 1992.

Belli, Gioconda: La mujer habitada. Managua: Vanguardia, 1988. Sofía de los presagios. Managua: Vanguardia, 1990. Waslala. Managua: Anamá, 1996.

Benjamin, Jessica: Die Fesseln der Liebe. Pschoanalyse, Feminismus und das Problem der Macht. Frankfurt a. M.: Fischer Taschenbuch Verlag, 1993. Original: The Bonds of Love. Psychoanalysis, Feminism, and the Problem of Domination. New York: 1988.

Dröscher, Barbara “La muerte de las madres”. Acercamientos a Carmen Boullosa-Actas del Simposio “Conjugarse al infinitivo”. Barbara Dröscher y Carlos Rincón, eds. Berlin: Ed. Tranvía, 1999. 59-67.

“Travesía, travestí y traducción. Posiciones in-between en la nueva novela historiográfica de América Central”. Revista de Estudios Sociales: (Universidad de los Andes), Tomo XIII, Octubre 2002, 81-89.

"Huérfanas y otras sin madre”. Revista de critica literaria latinoamericana 58 Lima-Hanover. (en prensa)

Fauné, María Angélica. "Las familias, las mujeres: qué dice la realidad”. envío UCA (Managua), Junio 1995, 39-47.

Gallegos, Rómulo. Doña Barbara. [1929] Madrid: Catedra, 2001. 
Guardia, Gloria. El último juego. San José: EDUCA, 1976.

Libertad en llamas. México: Ave Fénix, 1999.

Isaacs, Jorge: Maria. [1867] Madrid: Catedra, 2002.

Kristeva, Julia. “ Bakhtine, le mot, le dialogue e le roman”. Critique XXIII (1967): 438465.

Lobo, Tatiana. Asalto al paraíso. San José: Editorial de la Universidad de Costa Rica, 1992.

Marmol, José. Amalia [1855]. Madrid:Cátedra, 2000.

Martínez S., Luz Ivette. Carmen Naranjo y la narrativa femenina en Costa Rica. San José: Educa, 1987.

Masiello, Francine. “Texto, ley, transgresión: Especulación sobre la novela (feminista) de vanguardia”. Revista Iberoamericana LI/132-133 (1985): 808-822.

Mondragón, Amelia. "Literatura y literaturas en Centroamérica”. Cambios estéticos y nuevos proyectos culturales en Centroamérica. Washington DC: Literal Books, 1993. 11-24.

Naranjo, Carmen. Sobrepunto. San José: EDUCA, 1985.

Pincón Garfield, Evelyn. Entrevista con Carmen Naranjo. Revista de la Escuela de Literatura y Ciencias del Lenguaje. Universidad Nacional. Letras 11-12 (Heredia, Costa Rica, enero-diciembre 1983): 215-228.

Rodríguez, Ileana. House/Garden/Nation: Space, Gender, and Ethnicity in Postcolonial Latin American Literatures by Women. Durham/London: Duke University Press, 1994.

Women, Guerrillas and Love-Understanding War in Central America. Minnesota/ London: University of Minnesota Press, 1996.

Sommer, Doris. Foundational fictions. The National Romances of Latin America. Berkeley/Los Angeles/London: University of California Press, 1991. 